\title{
Effects of Hypofractionated and Standard Fractionated Irradiation of Mice Heads with Gamma-Rays and Protons on Their Pheripheral Blood Parameters and Behavior
}

\author{
K. Sh. Voskanyan ${ }^{1}$, A. V. Rzyanina ${ }^{1}$, D. M. Borowicz ${ }^{1,2}$, G. V. Mitsyn ${ }^{1}$, V. N. Gaevsky ${ }^{1}$ and A. G. Molokanov ${ }^{1}$ \\ 1. Joint Institute for Nuclear Research, Dubna, Russia \\ 2. Department of Medical Physic, the Greater Poland Cancer Centre, Poznan, Poland
}

\begin{abstract}
Experiments were performed to study the action of fractionated irradiation of mice heads with $\gamma$-rays and protons on their peripheral blood parameters and behavior by the "Open Field" test. Mice were irradiated in two variants of fractionated irradiation: (1) traditional fractionation (in radiation therapy): 2 Gy once a day, 5 times a week, the total radiation dose 20 Gy; (2) extreme hypofractionation: $10 \mathrm{~Gy}$ once a week, on Mondays, the total radiation dose $20 \mathrm{~Gy}$. The results of the study showed that irradiation of mice heads has no effect on their peripheral blood parameters in both variants of the applied fractionated irradiation and the behavior of mice does not depend on the type of ionizing radiation and the variant of fractionated exposure that we used. On the basis of these results it can be concluded that the option of extreme hypofractionation we have chosen can successfully replace traditional fractionation, which in some cases is applied when carrying out radiotherapy for treating brain tumors. The application of this type of fractionation can lead to shorter terms of radiotherapy and bigger patient capacity of medical centers that conduct radiotherapy.
\end{abstract}

Key words: Radiation therapy, normal tissue, traditional fractionation, extreme hypofractionation.

\section{Introduction}

The application of ionizing radiation in radiotherapy of oncologic diseases is based on differences in radiosensitivity of the tumor and normal tissues. It is well-known that alternative processes occur at the action of ionizing radiation on biological objects: cell damage and repair, when normal tissues, because of the stable neurohumoral ties with the organism restore damages faster and fuller than the tumor (due to its autonomy). The development of ray therapy has led to the introduction of various modes of dose fractionation that have gradually become "traditional" in different countries. For example, according to the Manchester school, a course of radical ray therapy consists of 16 fractions and is held for over 3 weeks, while in the USA 35-40 fractions are held for 7-8 weeks. In Russia radical treatment is

Corresponding author: Dr. K. Sh. Voskanyan, leading scientific researcher, research fields: radiation biology, radiotherapy, radioprotection, photobiology. considered traditional of fractionation of 1.8-2 Gy once a day, 5 times a week up to the total doses that are defined by the tumor morphological structure and tolerance of normal tissues located in the irradiation area (usually, in the limits of 60-70 Gy) [1].

For recent decades, much improvement has been introduced into radiotherapy of malignant tumors in head and neck. Gradual application of the method of radiotherapy intensity modulation, the use of multimodality of the volume images of target and organs in the risky zone, as well as the employment of alternative schemes of fractionation and the accompanying administration of chemotherapy or target-oriented agents brought about the growth in efficiency of radiotherapy [2]. At the same time, high pace of modern life, lack of interest in patients in the prolonged (economically more expensive) ray treatment demand a search for alternative methods to solve the problem, and one of them is hypofractionation [3]. There are two approaches to 
hypofractionation in radiotherapy. The first is "moderate" hypofractionation that shortens the total period of treatment to 4-5.5 weeks, enlarging the fraction dimension from about 2.4 to $3.1 \mathrm{~Gy}$. The second approach is "extreme" hypofractionation when fractions reach the range from 4.7 to $8.0 \mathrm{~Gy}$, shortening the treatment period to the level of two-two and a half weeks [4].

We conducted experiments earlier to obtain information on possible repair of normal tissue after irradiation with gamma rays and to compare acute and fractionated irradiation of mice fibroblast cells $\mathrm{C} 3 \mathrm{H} 10 \mathrm{~T} 1 / 2$ in conditions close to clinical in maximum. We used $\gamma$-rays ${ }^{60} \mathrm{Co}$ in total dose from 4 to 20 Gy (the value of one fraction $2 \mathrm{~Gy}$, time interval between fractions-24 hours, 5 times a week) [5]. It turned out that with increasing of the irradiation dose the difference (on the criterion of cell survival) between fractionated and acute irradiation decreases, and at the dose of 20 Gy it was not observed. That meant that with the increase of the irradiation dose, the value of the irreversible component of the ray damage of cells grows (the number of nonreparable damages increases). On the basis of these results, this paper studied the effect of fractionated irradiation (traditional and hypofractionated) of mice heads with $\gamma$ - rays and protons on their peripheral blood parameters and behavior by the "Open Field" test.

\section{Methods}

The experiments were conducted in outbred mice (females) CD1 with mass of 25-31 g, in accordance with bioethical rules of conducting research in animals [6]. The animals were fed with the standard briquetted feeding staff and drinking water from drinking cups.

Before killing, the mice were weighed, then some blood was taken from their tails to calculate the number of leucocytes of peripheral blood and to determine the content of hemoglobin in blood; and then the mice were killed with the method of cervical dislocation. To calculate the amount of karyocytes of the bone marrow, a portion of bone marrow was taken from the mouse's thigh with a syringe; it was suspended in $4 \mathrm{~mL}$ of the $3 \%$ solution of acetic acid. To determine the content of hemoglobin in blood, we used the measuring device "Gemoglobinometr Mini-Gem 540" (CJSC scientific-industrial enterprise TEKHNOMEDIKA, Russia). The number of blood leucocytes and karyocytes was calculated with the Goryaev chamber according to the conventional methods [7].

\subsection{The Procedure of the "Open Field" Test}

It is well-known that application of ray therapy that is necessary in most cases of the treatment of brain tumors can lead to development of late effects in the form of endocrine disorders, decrease of intellectual qualities and cognitive ability, disorders in functions of sense organs [8].

The behavior of mice on the "Open Field" test [9] was checked at different time limits after the last day of irradiation. The test consists of quantitative measurement of behavior components of the animal placed into new open space-the arena (Fig. 1).

Normally, horizontal and VLA (vertical locomotors activity), grooming, hole, hole sniffing, defecation and urination, freezing and entry in the arena center are registered in the "Open Field" test.

After the test the mice were killed to determine the peripheral blood parameters and amount of the bone marrow karyocytes. The studies of blood in hematological groups were conducted on the 7 th, the 15 th and the 30th day after irradiation. The total control period of observation was 30 days.

\section{Irradiation}

The irradiation of mice was conducted in the MTC (Medical-Technical Complex) of the Laboratory of Nuclear Problems of the Joint Institute for Nuclear Research that is used for hadron therapy of oncological diseases [10]. $660 \mathrm{MeV}$ protons extracted from the phasotron accelerator were decelerated in 


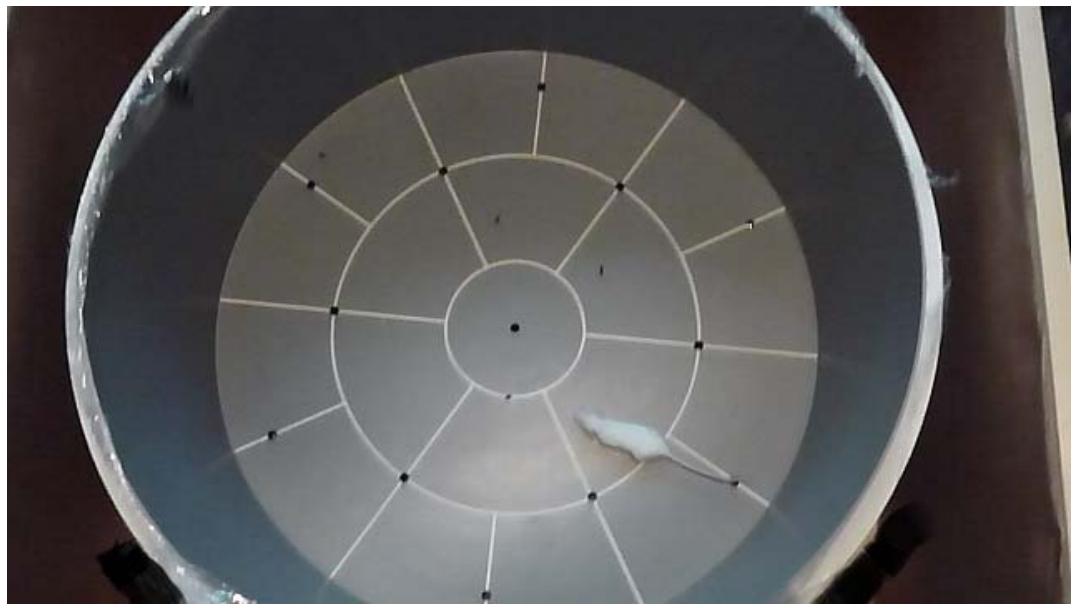

Fig. 1 The test arena "Open Field".

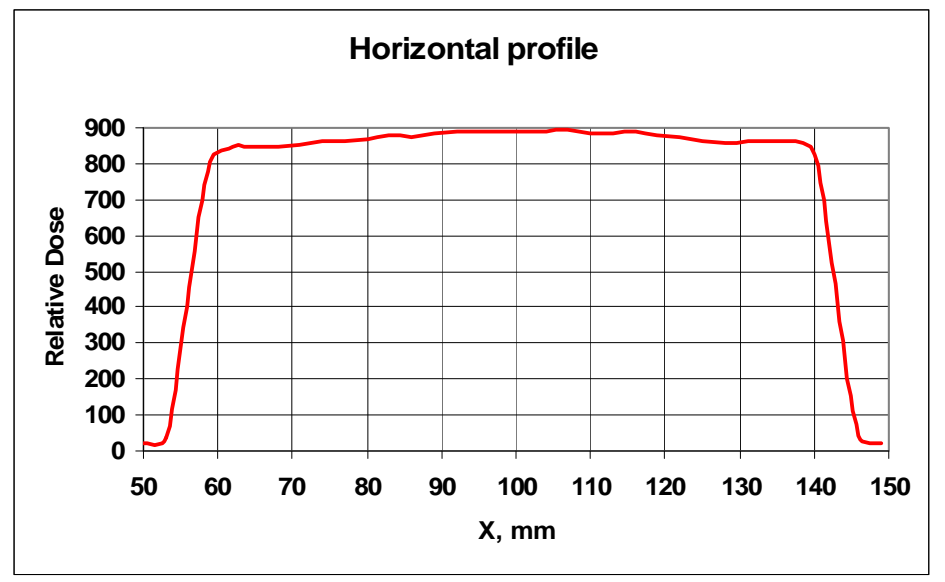

Fig. 2 The horizontal profile of the proton beam.

carbonic sets. After collimation and magnetic analysis the proton beam was transported to one of the MTC rooms for patient irradiation. The average energy of the proton beam at the input of the cabin was determined with the semiconductor Si detector on the beam passage in water $(\mathrm{R}=200 \mathrm{~mm}$ of water) and equaled to $171 \mathrm{MeV}$. The irradiation of mice was conducted with additional moderator $12 \mathrm{~mm}$ thick of water equivalent. The beam energy in the irradiation point was $\approx 150 \mathrm{MeV}$.

The beam dose calibration was done in each point of the depth dose distribution using the clinical dosimeter PTW UNIDOS-E (of the company "PTWFreiburg", Germany) with ionization chamber TM30013. Depth and horizontal dose distribution are shown in Figs. 2 and 3. The transverse dimensions of the beam in the irradiation point were $8 \mathrm{~cm} \times 8 \mathrm{~cm}$ on $90 \%$-isodose (Fig. 2). For homogeneous irradiation of mice in depth, the beam energy spectrum was transformed with a special device-a ridge filter. As a result, a flat maximum of ionization about $50 \mathrm{~mm}$ long was formed in the beam depth dose distribution (Fig. 3).

The mice were irradiated on the flat vertex of the modified Bragg peak (Fig. 3). The LET value in the Bragg peak input was $\sim 0.54 \mathrm{KeV} / \mathrm{mkm}$, in the Bragg peak $\sim 1.4 \mathrm{KeV} / \mathrm{mkm}$ (dose rate $\sim 0.5 \mathrm{~Gy}$ and $\sim 1 \mathrm{~Gy}$, correspondingly).

Gamma-therapy device ROCUS-M ("Ravenstvo" Co, St-Petersburg, Russia), with $\mathrm{Co}^{60}$ source and 7,600 Ku activity was used for the gamma-irradiation of mice (LET $\sim 0.3 \mathrm{KeV} / \mathrm{mkm}$, dose rate $\sim 0.87 \mathrm{~Gy} / \mathrm{min}$ ). 


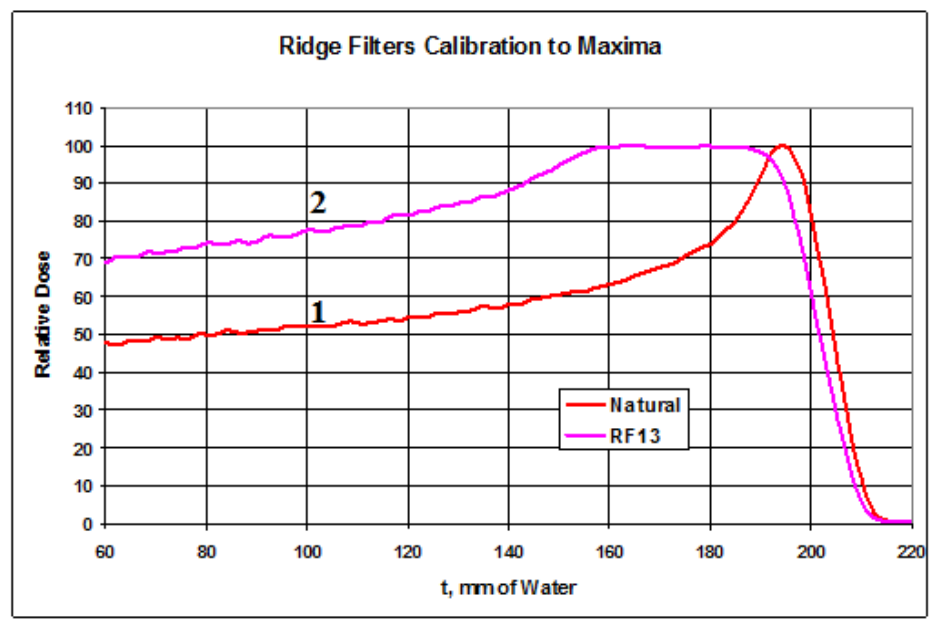

Fig. 3 Depth dose distribution of the proton beam-a natural beam (1) and a modified beam (2) with a ridge filter.

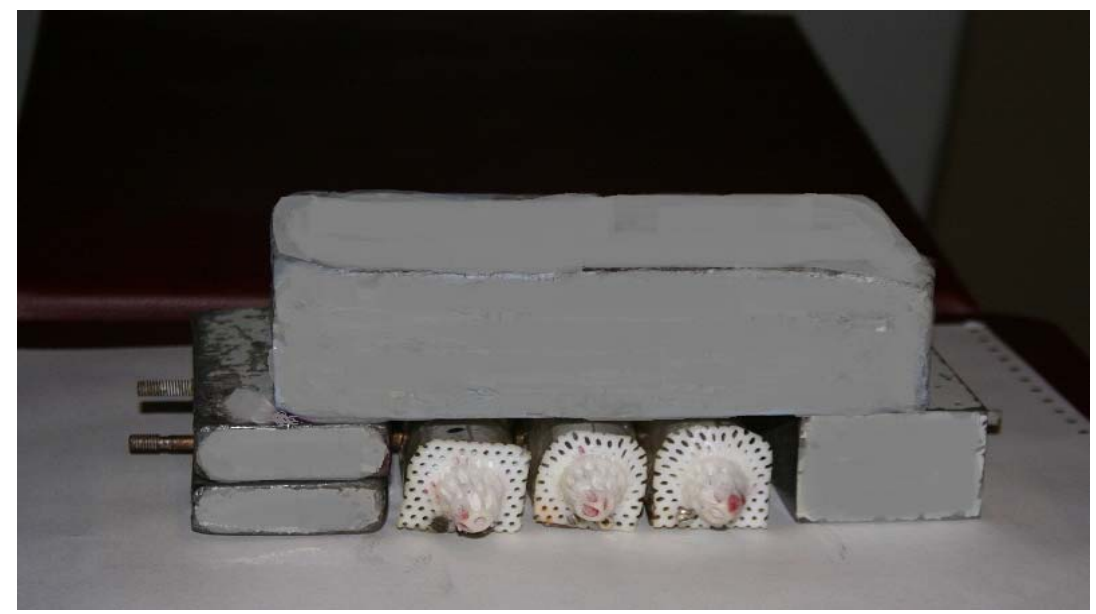

Fig. 4 Irradiation of mice's heads with gamma-radiation.

The dose rate of the gamma source was measured with the dosimeter PTW UNIDOS-E with an ionization chamber TM30013-03378 with a fully open collimator (the collimator dimensions $26 \mathrm{~cm} \times 22 \mathrm{~cm}$ ).

During the irradiation procedure the mice were put each one separately into frames with special protruded spouts for their heads' position. The frames were put in one line for irradiation with $\gamma$-rays, and then they were covered with lead blocks of $20 \mathrm{~cm}$ (length) $\times 10$ $\mathrm{cm}$ (width) $\times 5.5 \mathrm{~cm}$ (thickness) (Fig. 4). It should be stressed that the thickness of $5.5 \mathrm{~cm}$ corresponds to the standards of protective blocks used in radiotherapy, and the dose $10 \mathrm{~Gy}$ is lethal for mice at irradiation of the whole body [11]. To irradiate the mice with protons, the frames were put in pairs in two parallel levels, with the spouts facing each other (Fig. 5).

The mice were irradiated with ionizing radiation in two variants of fractionated irradiation:

(1) Traditional fractionation: 2 Gy once a day, 5 times a week, the total irradiation dose $20 \mathrm{~Gy}$;

(2) Extreme hypofractionation: 10 Gy once a week, on Mondays, the total radiation dose $20 \mathrm{~Gy}$.

\section{Results}

Table 1 contains the values of the peripheral blood parameters and bone marrow karyocytes of intact mice, as well as the values of the same parameters of the mice that underwent gamma irradiation in total dose of $20 \mathrm{~Gy}$ in different timing after irradiation.

The values of the peripheral blood parameters and 
bone marrow karyocytes in the mice that were different timing after irradiation are presented in irradiated with protons in total dose of 20 Gy in Table 2.

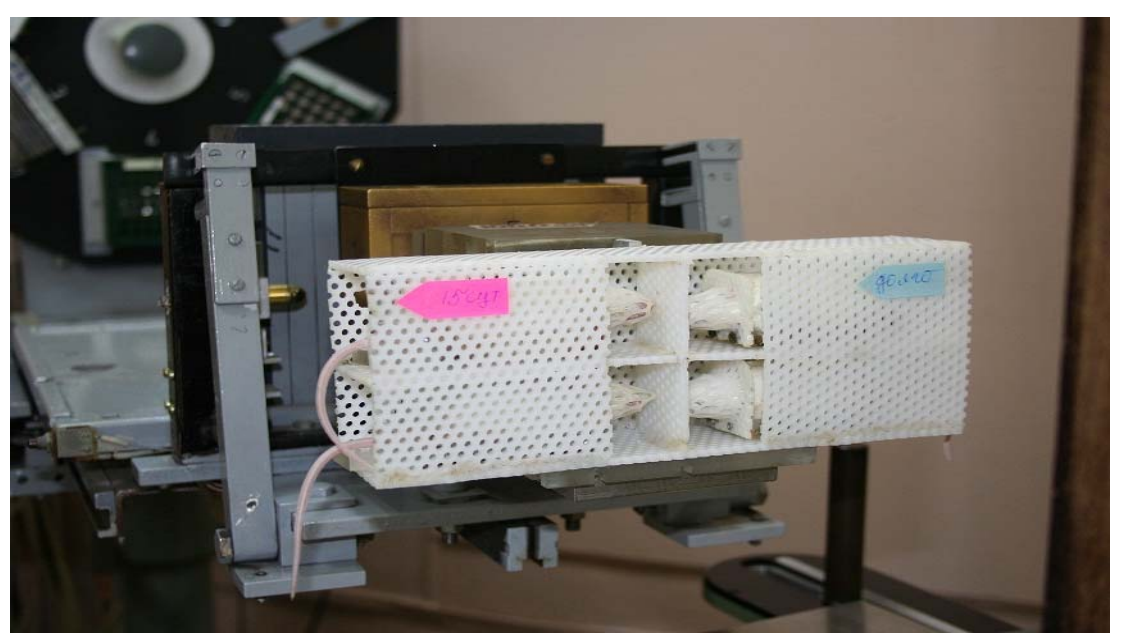

Fig. 5 Irradiation of mice's heads with protons.

Table 1 Values of the peripheral blood parameters and bone marrow karyocytes of intact mice, as well as the values of the same parameters of the mice that underwent gamma irradiation in total dose of $20 \mathrm{~Gy}$ in different timing after irradiation.

\begin{tabular}{|c|c|c|c|c|}
\hline The number of mice & Body mass, $\mathrm{g}$ & Hemoglobin, $g / L$ & Leukocytes,$\times 10^{3} \mathrm{mcl}$ & Karyocytes, $\times 10^{3} \mathrm{mcl}$ \\
\hline \multicolumn{5}{|l|}{ Intact mice } \\
\hline 7 & $28.2 \pm 1.7$ & $152 \pm 30$ & $3 \pm 0.7$ & $40 \pm 9$ \\
\hline \multicolumn{5}{|c|}{$(7$ days after exposure $) 10 \mathrm{~Gy} \times 2$} \\
\hline 7 & $26.1 \pm 1.8$ & $148.9 \pm 11.6$ & $3 \pm 1.2$ & $27.9 \pm 6.4$ \\
\hline \multicolumn{5}{|c|}{$(7$ days after exposure $) 2 \mathrm{~Gy} \times 10$} \\
\hline 7 & $25.2 \pm 1.6$ & $149.4 \pm 21.8$ & $2.2 \pm 0.4$ & $38 \pm 3.5$ \\
\hline \multicolumn{5}{|c|}{ (15 days after exposure) $10 \mathrm{~Gy} \times 2$} \\
\hline 7 & $29 \pm 1.2$ & $158.6 \pm 19.8$ & $2.7 \pm 0.2$ & $38.4 \pm 8.4$ \\
\hline \multicolumn{5}{|c|}{$(15$ days after exposure) $2 \mathrm{~Gy} \times 10$} \\
\hline 7 & $26.2 \pm 2.1$ & $161.6 \pm 43$ & $2 \pm 0.5$ & $27.7 \pm 6.7$ \\
\hline \multicolumn{5}{|c|}{ (30 days after exposure) $10 \mathrm{~Gy} \times 2$} \\
\hline 7 & $30 \pm 3.3$ & $183.4 \pm 41.5$ & $3.2 \pm 1$ & $34.8 \pm 7.7$ \\
\hline \multicolumn{5}{|c|}{$(30$ days after exposure) $2 \mathrm{~Gy} \times 10$} \\
\hline 7 & $31 \pm 2$ & $200.8 \pm 60$ & $2 \pm 0.8$ & $35.8 \pm 4.3$ \\
\hline
\end{tabular}

Table 2 The values of the peripheral blood parameters and bone marrow karyocytes of intact mice, as well as the values of the same parameters of the mice that were irradiated with protons in the total dose of $20 \mathrm{~Gy}$.

\begin{tabular}{|c|c|c|c|c|}
\hline The number of mice & Body mass, $g$ & Hemoglobin, g/L & Leukocytes, $\times 10^{3} \mathrm{mcl}$ & Karyocytes, $\times 10^{3} \mathrm{mcl}$ \\
\hline \multicolumn{5}{|l|}{ Intact mice } \\
\hline 7 & $34 \pm 3$ & $153 \pm 20$ & $3.1 \pm 0.9$ & $39 \pm 6$ \\
\hline \multicolumn{5}{|c|}{$(15$ days after exposure) $10 \mathrm{~Gy} \times 2$} \\
\hline 7 & $27 \pm 2.5$ & $164 \pm 10$ & $2.6 \pm 0.6$ & $32 \pm 4$ \\
\hline \multicolumn{5}{|c|}{ (15 days after exposure) $2 \mathrm{~Gy} \times 10$} \\
\hline 7 & $28 \pm 3$ & $160 \pm 24$ & $2.6 \pm 0.8$ & $43 \pm 12$ \\
\hline \multicolumn{5}{|c|}{ (30 days after exposure) $10 \mathrm{~Gy} \times 2$} \\
\hline 7 & $32 \pm 1.4$ & $156 \pm 11$ & $2.8 \pm 1.3$ & $40 \pm 8$ \\
\hline \multicolumn{5}{|c|}{ (30 days after exposure) $2 \mathrm{~Gy} \times 10$} \\
\hline 7 & $30 \pm 1.3$ & $143 \pm 23$ & $1.6 \pm 0.5$ & $40 \pm 5$ \\
\hline
\end{tabular}


Table 3 The behavior of mice 30 days after irradiation of $\gamma$-rays in total dose of $20 \mathrm{~Gy}$.

\begin{tabular}{lllllllll}
\hline Group & Number of sectors & $\begin{array}{l}\text { Entry in the } \\
\text { center }\end{array}$ & VLA & Grooming & Freezing & Hole & Defecation & Urination \\
\hline Intact mice & 129 & 6.3 & 26 & 0.3 & 0 & 9 & 2.2 & 0 \\
$10 \mathrm{~Gy} \times 2$ & 117 & 5.4 & 20 & 2 & 1.4 & 2.7 & 3.4 & 0 \\
$2 \mathrm{~Gy} \times 10$ & 125 & 3.8 & 24.3 & 1.3 & 0.8 & 3.8 & 1.8 & 0.2 \\
\hline
\end{tabular}

Table 4 The behavior of mice after various periods of irradiation by protons in the total dose of $20 \mathrm{~Gy}$.

\begin{tabular}{|c|c|c|c|c|c|c|c|c|}
\hline Group & $\begin{array}{l}\text { Number of } \\
\text { sectors }\end{array}$ & $\begin{array}{l}\text { Entry in the } \\
\text { center }\end{array}$ & VLA & Grooming & Freezing & Hole & Defecation & Urination \\
\hline Intact mice & 126 & 9.5 & 23 & 1.2 & 0.4 & 6 & 0.2 & 0 \\
\hline $\begin{array}{l}10 \mathrm{~Gy} \times 2 \\
15 \text { days }\end{array}$ & 125 & 7.5 & 19 & 1.7 & 1 & 3.3 & 1 & 0 \\
\hline $\begin{array}{l}2 \mathrm{~Gy} \times 10 \\
15 \text { days }\end{array}$ & 135 & 4.4 & 19 & 1.7 & 0.9 & 3 & 1 & 0.1 \\
\hline $\begin{array}{l}10 \mathrm{~Gy} \times 2 \\
30 \text { days }\end{array}$ & 107 & 5.3 & 21 & 1.6 & 0.8 & 2.5 & 1.9 & 0 \\
\hline $\begin{array}{l}2 \mathrm{~Gy} \times 10 \\
30 \text { days }\end{array}$ & 124 & 6 & 21 & 1.3 & 0.4 & 2.7 & 0.6 & 0 \\
\hline
\end{tabular}

Tables 3 and 4 present behavior of mice through 30 days after irradiation of $\gamma$-rays (3) and protons (4) in different periods after total irradiation dose of $20 \mathrm{~Gy}$.

\section{Discussion}

The results given in Table 1 show that the peripheral blood parameters of the irradiated mice, beyond all doubt, do not differ from the peripheral blood parameters of intact mice (in all periods after irradiation and for both variants of fractionation). The same picture is observed in case of irradiation of mice with protons (Table 2). On the basis of these results, it can be concluded that irradiation of mice's heads in both applied fractionation variants does not influence the parameters of their peripheral blood.

Studying the mice behavior in the test "Open Field" 30 days after $\gamma$-irradiation with the total dose of $20 \mathrm{~Gy}$ (Table 3), we observed the obvious difference in behavior of exposed and intact mice. Intact mice did not show anxiety after being placed into new open space (arena) of the set-up; they demonstrated high (especially in first minutes) horizontal and vertical activity, frequently peeping into holes and visits to the central part of the arena, no freezing and urination and rare grooming episodes. In the groups of irradiated mice (Table 3) the number of visits to the centre decreased, the number of hole-searches lowered, as well as horizontal and vertical activity. The number of freezing acts and grooming sessions grew. It all indicated to the increase of anxiety of irradiated mice, their emotional tension and degradation of exploratory faculties.

The differences in mice behavior 30 days after irradiation with $\gamma$-rays served the basis to study the behavior of mice in earlier periods after the exposure to protons. It turned out that (Table 4) the difference in behavior of intact and irradiated mice reveals on the $15^{\text {th }}$ day after proton irradiation and does not worsen quantitatively up to 30 days; with that, the behavior deviation does not differ from that of mice exposed to $\gamma$-rays. The results of the experiments given in Tables 3 and 4 also showed that the mice's behavior does not depend on the type of ionizing radiation and the variant of the applied fractionated irradiation.

\section{Conclusions}

It can be concluded on the basis of the results obtained in the research that the variant of extreme hyperfractionation that we chose can successfully replace traditional fractionation which is applied in some cases in radiotherapy to treat brain tumors. The application of the discussed type of fractionation can reduce the period of radiotherapy course and increase the capacity of medical radiotherapy centers. 

Protons on Their Pheripheral Blood Parameters and Behavior

We would like also to mark in the conclusion that clinical tests have been successfully conducted lately with application of hyperfractionation in those cases when usually traditional prolonged courses of tumor irradiation had been used [12, 13], including the cases when the tumor irradiation scheme was applied-once a week $[14,15]$, and in palliative ray therapy $[16,17]$.

\section{References}

[1] Boiko, A. V., Chernichenko, A. V., Darialova, S. L., Meshcheryakova, I. A., and Ter-Arutyunyants, S. A. 2001. "Unconventional Dose Fractionation." In Proceedings of V Russian Oncological Conference, 27-9.

[2] Grégoire, V., Langendijk, J. A., and Nuyts, S. 2015. "Advances in Radiotherapy for Head and Neck Cancer." J Clin Onco 33 (29): 3277-84.

[3] "Opportunities of hyperfractionation in proton therapy are studied in the Institute of Proton Therapy of Florida University."

$\mathrm{http} / / /$ protontherapy.ru/v_institute_protonnoj_terapii_uni versiteta_floridy_izuchajut_vozmozhnosti_gipofrakcionir ovania_v_protonnoj_terapii/.

[4] Dengina, N. V. "The Year 2015 in Its Climax: Hyperfractionation is Coming." http://www.rosoncoweb.ru/news/oncology/2015/.

[5] Voskanyan, K. Sh., Mitsyn, G. V., and Gaevsky, V. N. 2005. "Efficiency of Biological Action of Protons and Gamma-Radiation on C3H10T1/2 Cells." Aviokosmicheskaya I Ekologicheskaya Meditsina (Aerospace and ecological medicine) 39 (5): 50-3.

[6] Genin, A., Iljin, E., Kaplansky, A., and Kasatkina, K. 2001. "Bioethical Regulations of Conducting Research on Man and Animals in Aviation, Space and Naval Medicine." Aviokosmicheskaya I Ekologicheskaya Meditsina 35 (4): 14-20.

[7] Koblov, F. 1979. Methods and Devices for Clinical and Laboratory Research. Moscow: Meditsina.

[8] Shcherbenko, O. I. "Remote Effects of Ray Therapy of Brain Tumors (Literature Review)." http://vestnik.rncrr.ru/vestnik/v12/papers/sherb2_v12.htm
[9] Brown, R. E., Corey, S. C., and Moore, A. K. 1999. "Differences in Measures of Exploration and Fear in MHC-Congenic C57BL/6J and B6-H-2K Mice." Behavior Genetics 1999 (29): 263-71.

[10] Savchenko, O. V. 1996. "Status and Prospects of New Clinical Methods of Cancer Diagnostics and Treatment Based on Particle and Ion Beams Available at JINR." In Communication of the Joint Institute for Nuclear Research, Dubna.

[11] Shashkov, V. S., Karsanova, S. K., and Yasnetsov, V. V. 2007. "Comparative Protective Action of Radioprotectors and Screening in $\gamma$-Irradiation of Mice." Aviokosmicheskaya I Ekologicheskaya Meditsina (Aerospace and ecological medicine) 41 (3): 39-43.

[12] Arvold, N. D., Tanguturi, S. K, Aizer, A. A. et al. 2015. "Hypofractionated versus Standard Radiation Therapy with or without Temozolomide for Older Glioblastoma Patients.” Int J Radiat Oncol Biol Phys. 92 (2): 384-9.

[13] Westover, K., Loo, Jr. B. W., and Gerber, D. E. et al. 2015. "Precision Hypofractionated Radiation Therapy in Poor Performing Patients with Non-Small Cell Lung Cancer: Phase 1 Dose Escalation Trial." Radiother Oncol 93 (1): 72-81.

[14] Chargari, C., Pena, C. P., and Toledano, I. et al. 2012. "Concurrent Use of Aromatase Inhibitors and Hypofractionated Radiation Therapy." World J Radiol 4 (7): 318-23.

[15] Dash, C., Demas, K., and Uhm, S. et al. 2012. "Low Incidence of Fatigue after Hypofractionated Stereotactic Body Radiation Therapy for Localized Prostate Cancer." Radiation Oncology 2 (142): 1-6.

[16] Matoba, M., Oota, K., Tonami, H. et al. 2010. "Palliative Radiotherapy with $1 \times 8$ Gy Using Conformal Radiotherapy for Chemotherapy-Refractory, Recurrent, Aggressive Lymphomas." Japanese Journal of Radiology 28 (3): 220-3.

[17] Gumeneckaya, Yu. V., Mardinskii, Yu. S., Karyakin, O. B., and Gulidov. I. A. 2009. "Opportunities and Prospects of the Application of Accelerated Fractionation Courses in Palliative Radiotherapy in Patients with Bladder Cancer." Siberian Oncology journal 33 (3): 15-9. 